\title{
Prognostic Importance of the Risk-check Examination (RISIKOCHECK®) for Patients with Bladder Cancer
}

\author{
Abdulkadir Yildiz ${ }^{1}$, Necmettin Aydin Mungan ${ }^{2}$, Adem Tok $^{2} *$, Ibrahim Donmez ${ }^{3}$, \\ Bulent Erol $^{4}$,Tamer Aliskan ${ }^{2}$, Izzet Cicekbilek ${ }^{2}$, Bulent Akduman ${ }^{2}$ \\ ${ }^{1}$ Department of Urology, Yunus Emre State Hospital, Eskisehir, Turkey \\ ${ }^{2}$ Department of Urology, Faculty of Medicine, Bülent Ecevit University, Zonguldak, Turkey \\ ${ }^{3}$ Department of Urology, Asikpasa Private Hospital, Kirsehir, Turkey \\ ${ }^{4}$ Department of Urology, Faculty of Medicine, Medeniyet University, Istanbul, Turkey \\ ademtok2003@yahoo.com
}

\begin{abstract}
Objectives: The computer software programme Risikocheck (RC@) was developed with consideration of these epidemiological data to evaluate bladder cancer risk. The objective of this study was to determine if there is a relationship between prognosis and the risk level obtained from an RC examination of patients with bladder cancer at the same stage and rate and were followed for 8 years.
\end{abstract}

Materials and Methods: Seventy-seven males and five females, who were diagnosed with primary and recurrent non-muscle-invasive bladder cancer (NMIBC) stage Ta-T1, grade 1-3 bladder tumors without carcinoma in situ $(C I S)$, were examined retrospectively. The risk groups of patients were determined by the RC programme. The relationships between risk groups and the pathological stage and grades of bladder tumors, prognosis, and recurrence number/period were examined.

Results: The relationship between tumor stage and the $R C$ risk groups was significant (p=0.007), but the relationship between tumor grade and $R C$ group was not significant $(p=0.835)$. The relationship between $R C$ risk group and progression $(p=0.005)$ and recurrence $(p=0.041)$ was significant. The relationship between the time to progression and recurrence and $R C$ were not significant ( $p=1.00$ and 0.566 , respectively). The relationship between the number of recurrences and $R C$ was not significant $(p=0.415)$.

Conclusion: The use of RC inquiry forms, which is a risk-based surveying method, may have prognostic value for estimating recurrence and progression of bladder cancer, which can occur on post transurethral resection of a bladder tumor (TUR-Bt) follow-up of bladder tumors that have NMIBC.

Keywords: Bladder cancer; risikocheck; recurrence; prognosis.

\section{INTRODUCTION}

Bladder cancer is the most frequently seen neoplasm of the urinary system and is detected fourfold more frequently in males than females. ${ }^{(1)}$ The nomograms and scoring systems that predict recurrence and progression of these tumors are insufficient even if patients are divided into low-, intermediateand high-risk groups by theWorld Health Organization (WHO) classification, as this classification makes distinction between recurrence and progression risk. The progression risk may be low or other tumors may carry a higher risk in terms of both recurrence and progression. TheEuropean Organisation for Research and Treatment of Cancer (EORTC) developed a scoring system and risk tables to predict the short- and long-term recurrence and progression risks separately by considering the number and size of tumors, previous recurrence rate, T category, CIS existence, and tumor grade. ${ }^{(2)}$ However, practical application of this scoring system is rare and is based only on bladder tumor pathology; predisposing factors for bladder cancer, such as smoking, exposure to carcinogens, including occupational and environmental factors, and patient demographic characteristics, are not considered.

A risk-based scanning method and risk estimation survey known as Risikocheck (RC) has been developed to increase the quality of bladder cancer detection and treatment. RC makes it possible to diagnose tumors early before symptoms occur. ${ }^{(3,4)}$ Studies of RC have aimed to diagnose and treat tumors early by identifying the risk group. However, no risk estimation survey in which risk factors in patients with bladder cancer are evaluated together has been performed. Determining the clinical application of and validating RC will provide clinicians with a more accurate approach to diagnosis 
and treatment of bladder cancer. Shariat et al. reported that nomograms increase patient tenacity and their interest in treatment. ${ }^{(5)}$ Awareness of disease stage, clinical importance, treatment complications, long-term morbidities, and estimated probability percentages will increase patient satisfaction posttreatment. Recent studies have trended on cell surface antigens and genetic markers for risk assessment. $^{(6,7)}$

In this study, we identified the stage, grade, progression and recurrence, time to progression and recurrence, and number of recurrences in patients with NMIBC without CIS and that were of identical stage and grade. We also evaluated the relationships between risk groups and the RC classification.

\section{Materials AND Methods}

A total of 82 patients [77 (93.9\%) males and five (6.1\%) females; mean age, $65.4 \pm 12.3$ years; range, 25-84 years] who were treated for primary or recurrent stage Ta-T1 (TNM staging system, 2002) or grades 1-3 (WHO Classification, 1974) bladder tumors and who were followed-up at our university hospital were included. Patients were included if they had the same stage and grade of tumor. Mean follow-up period was 24.2 (6-84) months after TUR-Bt. The presence of a tumor with identical or different characteristics and localization was evaluated as a recurrence and increases in stage and grade were considered progression. The RC inquiry form, which is a computer software package developed by Dr. Gerson Ludecke, was used. Age, gender, smoking years/number of cigarettes, and risk classification according to occupational group was included on the form. The patients were divided into low-, intermediate-, and high-risk groups according to the risk classification. Twenty-five patients ( 23 males and 2 females) were in the low-risk group. Twenty-nine patients (26 males and three females) were in the intermediate-risk group. Twenty-eight males were in the high-risk group. The objective was to determine the relationship between risk level obtained by the RC survey and disease prognosis.

Statistical analysis was performed with SPSS 13.0 software (SPSS, Inc., Chicago, IL, USA). Descriptive statistics were expressed as frequency and percent. The Chi-square test or Fisher Exact Chi-Square test was used to determine for difference between groups. $\mathrm{p}$ value of less than 0.05 was considered statistically significant for all tests.

\section{RESUlts}

The pathological stages of the 82 patients included in this study were as follows: 38 (46.3\%) were Ta (mucosal involvement), 44 (53.7\%) were T1 (sub-mucosal involvement, 19 (23.2\%) were G1 (low grade), $41(50 \%)$ were G2 (intermediate grade), and 22 (26.8\%) were G3 (high grade). According to RC, $25(30.5 \%)$ patients were at low risk, 29 (35.4\%) at intermediate risk, and 28 (34.1\%) at high risk. The relationship between RC and pathology is shown in Table 1.

Table1. Relationship between Risikocheck and pathology.

\begin{tabular}{|c|c|c|c|c|c|c|c|}
\hline \multirow[t]{3}{*}{ Pathology } & \multicolumn{6}{|c|}{ RISIKOCHECK } & \multirow{3}{*}{$\mathbf{p}$} \\
\hline & \multicolumn{2}{|c|}{$\begin{array}{c}\text { Low risk } \\
\mathrm{n}=25(30.5 \%)\end{array}$} & \multicolumn{2}{|c|}{$\begin{array}{c}\text { intermediate risk } \\
\mathrm{n}=\mathbf{2 9}(\mathbf{3 5 . 4 \%})\end{array}$} & \multicolumn{2}{|c|}{$\begin{array}{c}\text { High risk } \\
\mathrm{n}=28(34.1 \%)\end{array}$} & \\
\hline & $\mathbf{n}$ & $\%$ & $\mathbf{n}$ & $\%$ & $\mathbf{n}$ & $\%$ & \\
\hline $\mathrm{Ta}$ & 17 & 68 & 14 & 48.3 & 7 & 25 & \multirow[t]{2}{*}{0.007} \\
\hline $\mathrm{T} 1$ & 8 & 32 & 15 & 51.7 & 21 & 75 & \\
\hline G1 & 7 & 28 & 6 & 20.7 & 6 & 21.4 & \multirow[t]{3}{*}{$\mathbf{0 . 8 3 5}$} \\
\hline G2 & 10 & 40 & 16 & 55.2 & 15 & 53.6 & \\
\hline G3 & 8 & 32 & 7 & 24.1 & 7 & 25 & \\
\hline
\end{tabular}

The relationship between tumor pathology stage and RC risk group was significant $(p=0.007)$. Patients with a high risk on the $\mathrm{RC}$ were at a progressed stage, whereas patients in the low-risk group were at a considerably less advanced stage; however, the relationship between tumor grade and RC risk group was not significant $(\mathrm{p}=0.835)$.

Nine (11\%) of the eighty-two patients showed progression, and 19 (23.2\%) developed a recurrence. Of the nine patients with progression, eight $(88.9 \%)$ progressed from T1 to T2 (muscle involvement) and one $(11.1 \%)$ progressed form Ta to T1. Six of the eight patients who progressed to T2 had a high risk classification on the RC. Mean progression free survival was found as 10.7 (2-35) months. The relationship between RC risk group and pathology is shown in Figure 1. 

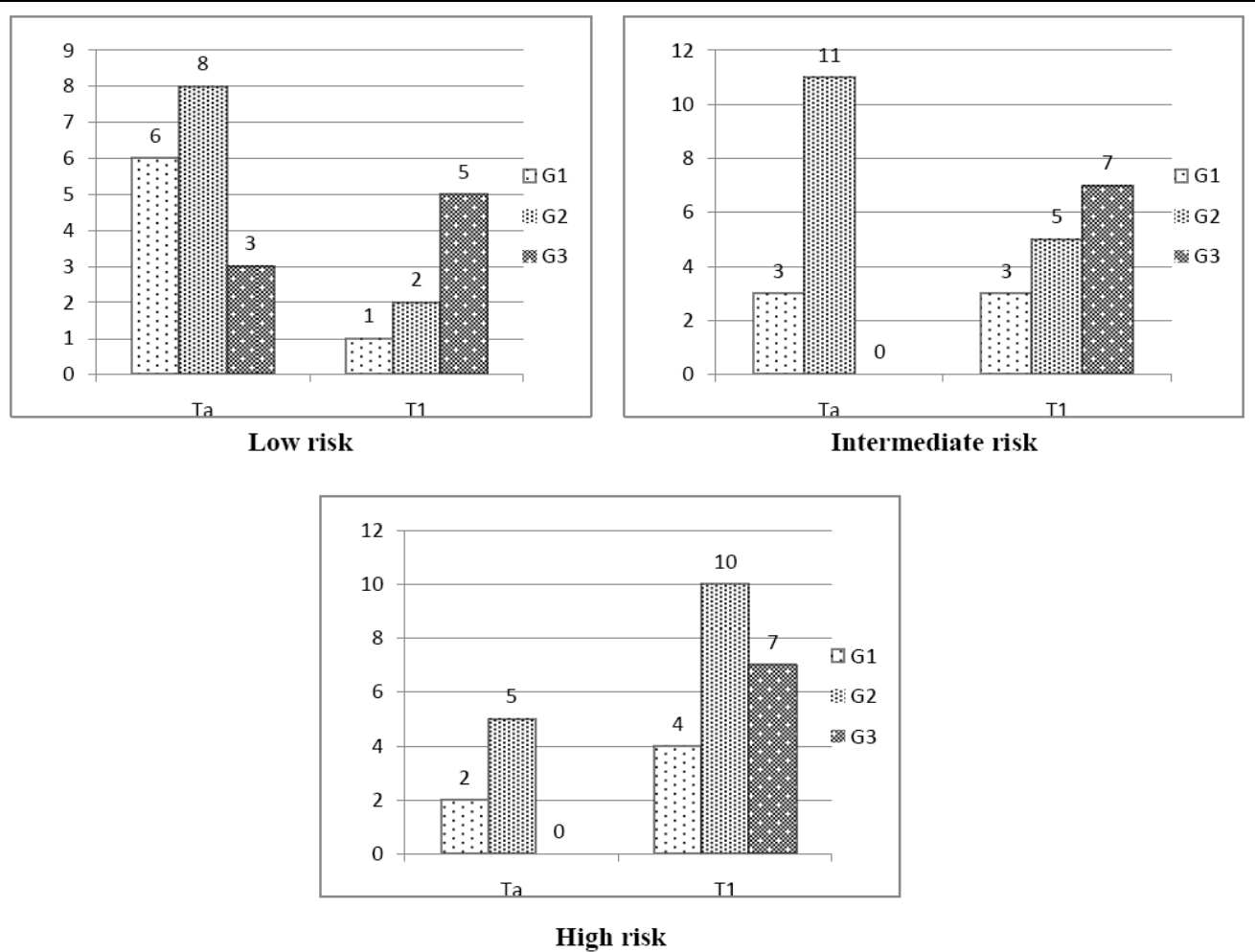

Figure1. Relationship between Risikocheck risk groups and pathology.

As no progression was observed in the low-risk patients, the recurrence ratio was $12 \%$. Of the intermediate-risk-group patients, progression occurred in $6.9 \%$ and the recurrence ratio was $17.2 \%$. The progression ratio was $25 \%$ and the recurrence ratio was $39.3 \%$ in the high-risk group. The relationship between RC risk group and recurrence and/or progression is shown in Table 2.

Table2. Relationship between progression and recurrence and the Risikocheck risk group.

\begin{tabular}{|c|c|c|c|c|c|c|c|c|}
\hline \multirow{3}{*}{\multicolumn{2}{|c|}{$\begin{array}{c}\text { Progression and } \\
\text { Recurrence }\end{array}$}} & \multicolumn{6}{|c|}{ RISIKOCHECK } & \multirow[b]{3}{*}{$\mathbf{p}$} \\
\hline & & \multicolumn{2}{|c|}{$\begin{array}{c}\text { Low risk } \\
\mathbf{n}=25\end{array}$} & \multicolumn{2}{|c|}{$\begin{array}{c}\begin{array}{c}\text { intermediate risk } \\
\mathrm{n}=29\end{array} \\
\end{array}$} & \multicolumn{2}{|c|}{$\begin{array}{c}\text { High risk } \\
\mathrm{n}=28\end{array}$} & \\
\hline & & $\mathbf{n}$ & $\%$ & $\mathrm{n}$ & $\%$ & $\mathbf{n}$ & $\%$ & \\
\hline \multirow[t]{2}{*}{ Progression } & No & 25 & 100 & 27 & 93.1 & 21 & 75 & \multirow{2}{*}{0.005} \\
\hline & Yes & 0 & $\mathbf{0}$ & 2 & 6.9 & 7 & 25 & \\
\hline \multirow{2}{*}{ Recurrence } & No & 22 & 88 & 24 & 82.8 & 17 & 60.7 & \multirow{2}{*}{0.041} \\
\hline & Yes & 3 & 12 & 5 & 17.2 & 11 & 39.3 & \\
\hline
\end{tabular}

The relationship between low and high risk was significant in the advanced analysis conducted to determine the cause of the difference between progression and $\mathrm{RC}(\mathrm{p}=0.011)$.

The relationship between low and high risk was significant in the advanced analysis conducted to determine the cause of the difference between recurrence and $\mathrm{RC}(\mathrm{p}=0.05)$.

Although number of recurrences increased with increasing risk category, the relationship between the number of recurrences and RC risk group was not significant $(\mathrm{p}=0.415)$. The relationship between the number of recurrences and $\mathrm{RC}$ risk group is shown in Table.3.

Table3. Relationship between the number of recurrences and the Risikocheck risk group.

\begin{tabular}{|c|c|c|c|c|c|c|c|}
\hline \multirow{3}{*}{$\begin{array}{l}\text { The number of } \\
\text { recurrences }\end{array}$} & \multicolumn{6}{|c|}{ RISIKOCHECK } & \multirow{3}{*}{$\mathbf{p}$} \\
\hline & \multicolumn{2}{|c|}{$\begin{array}{c}\text { Low risk } \\
\mathbf{n}=25\end{array}$} & \multicolumn{2}{|c|}{$\begin{array}{c}\text { intermediate } \\
\text { risk } \\
\mathbf{n}=\mathbf{2 9}\end{array}$} & \multicolumn{2}{|c|}{$\begin{array}{l}\text { High risk } \\
\mathbf{n}=28\end{array}$} & \\
\hline & $\mathrm{n}$ & $\%$ & $\mathrm{n}$ & $\%$ & $\mathrm{n}$ & $\%$ & \\
\hline 1 & 1 & 33.3 & 4 & 80 & 7 & 63.6 & \multirow{2}{*}{0.415} \\
\hline$\geq 2$ & 2 & 66.7 & 1 & 20 & 4 & 36.4 & \\
\hline
\end{tabular}


Most cases that progressed occurred within 1 year of follow up. As the risk ratio increased, the time that passed until progression and recurrence decreased. However, these relationships were not significant ( $\mathrm{p}=1.00$ and $\mathrm{p}=0.566$, respectively). The relationships between the time that passed until progression/recurrence and RC risk group are shown in Table.4.

Table4. Relationship between the time that passed during progression, recurrence, and Risikocheck.

\begin{tabular}{|c|c|c|c|c|c|c|c|c|}
\hline \multirow{3}{*}{\multicolumn{2}{|c|}{$\begin{array}{l}\text { The time that passed } \\
\text { during progression, } \\
\text { recurrence }\end{array}$}} & \multicolumn{6}{|c|}{ RISIKOCHECK } & \multirow{3}{*}{$\mathbf{p}$} \\
\hline & & \multicolumn{2}{|c|}{$\begin{array}{c}\text { Low risk } \\
\quad n=25\end{array}$} & \multicolumn{2}{|c|}{$\begin{array}{c}\text { intermediate } \\
\text { risk } \\
\mathbf{n = 2 9} \\
\end{array}$} & \multicolumn{2}{|c|}{$\begin{array}{l}\text { High risk } \\
\quad n=28\end{array}$} & \\
\hline & & $\mathbf{n}$ & $\%$ & $\mathbf{n}$ & $\%$ & $\mathbf{n}$ & $\%$ & \\
\hline \multirow[t]{2}{*}{ Progression } & $<1$ year & - & - & 1 & 50 & 5 & 71.4 & \multirow{2}{*}{1.000} \\
\hline & $\geq 1$ year & - & - & 1 & 50 & 2 & 28.6 & \\
\hline \multirow{2}{*}{ Recurrence } & $<1$ year & 3 & 100 & 4 & 80 & 9 & 81.8 & \multirow{2}{*}{0.566} \\
\hline & $\geq 1$ year & - & - & 1 & 20 & 2 & 18.2 & \\
\hline
\end{tabular}

\section{DISCUSSION}

Bladder tumors have a multi-factorial etiology in which chemical carcinogens occupy an important place. The most important etiological factor for both genders is smoking. ${ }^{(8)}$ Approximately $50 \%$ of males and $23 \%$ of females who develop bladder cancer smoke. ${ }^{(9)}$ It has been estimated that, in the UK, around $7.1 \%$ of bladder cancer cases in men and $1.9 \%$ in women are linked to occupational exposures. ${ }^{(10)}$ Phenacetin, chlornaphazine and cyclophosphamide also increase bladder cancer risk. ${ }^{(11)}$ $\mathrm{S}$. haematobium is a cause of squamous cell carcinoma. some medications and foods are other important etiological factors.

Besides the direct relationship between smoking duration and the occurrence of bladder cancer, there is also a close relationship with the number of cigarettes smoked daily. ${ }^{(1)}$ Available data suggest that starting smoking at an early age or long-duration exposure to cigarette-originating carcinogens increases the risk of bladder cancer. ${ }^{(9,12)}$ Aliasgari and co-workers demonstrated that, the incidence of bladder cancer in smokers, who are simultaneously opium consumers, was higher than in patients who were only smokers. ${ }^{(13)}$

The carcinogenic effect of cigarettes on bladder cancer is independent of gender. Jeffrey et al. obtained similar risk estimates for males and females with similar exposure to cigarette smoke, and reported no significant difference between genders and according to exposure to cigarette smoke. ${ }^{(14)}$ Although passive smoking is also a risk factor, being exposed to cigarette smoke is much less of a risk than is active smoking. ${ }^{(15)}$ Anthony et al. conducted a prospective cohort study to identify the effect of both active and passive smoking on bladder cancer and reported that active smoking was associated with an increased risk of bladder cancer. ${ }^{(15)}$

Genetic and epigenetic changes related to carcinogenesis in the bladder have been linked to environmental and occupational factors unrelated to cigarette smoking and may be an important cause of bladder cancer in non-smokers. ${ }^{(16)}$ Females who use permanent hair dye regularly have an increased risk of bladder cancer; the increase is greater if the dye contains slow acetylators. ${ }^{(17)}$

Many pre-cognition models that take into consideration these risk factors have been developed. Ludecke et al. developed a computer software package that identifies three sub-groups based on bladder cancer risk factors (gender and age, smoking habit, and exposure to carcinogenic toxins). This formula calculates automatically the subject's risk of developing bladder cancer. This formula allows urologists and general practitioners to identify those at risk of developing bladder cancer. As a result, clinicians are offered more objective data instead of subjective intuitive information from nomograms. ${ }^{(18)}$ This approach, which was developed further by Ludecke et al., has increased the probability of identifying patients with bladder cancer at an earlier stage. As a result, the need for scans, treatment costs, and mortality rates have decreased, and the treatment ratio has increased. ${ }^{(19)}$

A total of 1,205 recorded patients with bladder cancer (619 with bladder cancer and 586 without cystoscopic tumors) at nine centers participated in Ludecke's multi-center study. The results showed that RC detects bladder cancer with $62.5 \%$ accuracy, $71.5 \%$ sensitivity, and $52.3 \%$ specificity. The false-negative rate is $39.7 \%$, and an advanced sub-analysis showed that low-risk, non-invasive tumor cases accumulated in this group. ${ }^{(20)}$ 
We examined the prognostic importance of $\mathrm{RC}$ in patients with bladder cancer, and found a significant correlation between RC risk group and tumor stage. The increase in the RC risk group linearly with occupational exposure to carcinogens and tobacco use-and long-duration exposure, particularly in the high-risk group was explained by the correlation with tumor pathological stage.

However, no correlation was found between tumor grade and RC risk group, possibly due to the difference between the old (WHO, 1974) and new (WHO/ISUP, 2004) pathological classifications. That is; grade 3 in the old system matches high-grade papillary urethelial carcinoma (HGPUC) in the new system. No direct matching of grades 1 and 2 is made in the WHO classification. For example, grade 1 lesions may be assigned to low-malignancy-potential papillary urothelial neoplasms and sometimes to low-grade papillary urothelial carcinomas (LGPUC) in the new system. Grade 2 lesions in the old system include a wide spectrum, as these lesions may correspond to either LGPUC or HGPUC in the new system. ${ }^{(21)}$

The important problem regarding bladder cancers that are non-muscle-invasive is their recurrence rate of $50-70 \%$ and progression in $10-15 \%$ of cases. ${ }^{(21)}$

In our study, The relationships between the increased risk as determined by RC and progression and recurrence of disease were significant. When the number of recurrences increased, the risk category tended to increase, albeit not significantly. This may have been due to a number of reasons. First, the diverse follow-up durations. The second possible reason is the low number of patients, as evaluation of a greater number of patients would have increased the statistical power. A third possibility is the effect of intravesical chemotherapy or immunotherapy administered to the patients. In our study, patients treated with intravesical BCG progressed over the 2-year period, whereas non-treated patients showed earlier progression. The group of patients who were accepted as stage T1 may in reality have been stage T2. It has been determined that $9-49 \%$ of tumor staging is low. ${ }^{(2)}$ Consequently, as the treatment programs and risk levels differed, the period of progression in these patients may have been statistically insignificant. Differences in the abovementioned grade classification may have also affected progression. For this reason, the pathology of the patients in our study was re-evaluated by correlating the old and new systems. It was concluded that change in grade did not affect the period of progression. No significant difference in the rate and number of recurrences was observed between intravesically treated and untreated patients. However, $52.7 \%$ of the patients did not complete their treatment protocols for various reasons (cancer-related deaths, other deaths and loss to follow-up checks), which may have affected the time to recurrence and number of recurrences.

\section{Conclusion}

We conclude that the RC questionnaire form, which is a risk-based scanning method, can be used to predict recurrence and progression after TUR-Bt follow-up of bladder cancer tumors that have NMIBC. Our results suggest that as risk increased, the risk of recurrence and progression increased; this increased risk was not associated with tumor grade. No relationship was found between the time until progression and recurrence rate by RC. However, nomograms have limitations, and none provides a $100 \%$ accurate risk analysis. ${ }^{(21,22)}$ Thus, our results should be confirmed in further studies.

\section{REFERENCES}

[1] Ploeg M, Aben KKH, Kiemeney LA. The present and future burden of urinary bladder cancer in the world. World J Urol. 2009;27: 289-93.

[2] Sylvester RJ, Van der Meijden AP, Oosterlinck W, et al. Predicting recurrence and progression in individual patients with stage Ta T1 bladder cancer using EORTC risk tables: a combined analysis of 2596 patients from seven EORTC trials. Eur Urol. 2006;49:466-77.

[3] Govorov A. "6 th Meeting of the European Society of Oncological Urology". Expert Reviews Anticancer Ther. 2009;9:397-9.

[4] Martini T, Mayr R, Lodde M, Seitz C, Trenti E, Comploj E, Palermo S, Pycha A, Mian C, Zywica M, Weidner W, Lüdecke G. Validation of RiskCheck Bladder Cancer $\odot$, version 5.0 for risk-adapted screening of bladder cancer. Urol Int. 2013;91:175-81.

[5] Shariat SF, Margulis V, Lotan Y, et al : Nomograms for bladder cancer. Eur Urol. 2008;54:4153. 
[6] Falahatkar S, Donyamali H, Joafshani MA, et al. The comparison between human leukocyte antigen system incidence in patients with bladder cancer and normal controls. Urol $\mathrm{J}$. 2014;10:1059-62.

[7] Goyal S, Singh UR, Sharma S, Kaur N. Correlation of mitotic indices, AgNor count, Ki-67 and Bcl-2 with grade and stage in papillary urothelial bladder cancer. Urol J. 2014;11:1238-47.

[8] Van der Poel HG, Mungan NA, Witjes JA. Bladder cancer in women. Int Urogynecol J Pelvic Floor Dysfunct. 1999;10:207-12.

[9] Zeegers MPA, Kellen E, Buntinx F, et al. The association between smoking, beverage consumption, diet and bladder cancer: a systematic literature review. World Urol. 2004;21:392401.

[10] Parkin DM. Cancers attributable to occupational exposures in the UK in 2010. Br J Cancer. 2011;105:70-2.

[11] Murta-Nascimento C, Schmitz-Dräger B, Zeegers MP, et al. Epidemiology of urinary bladder cancer: from tumor development to patient's death. World J Urol. 2007;25:285-95.

[12] Zeegers MP, Tan FE, Dorant E, et al. The impact of characteristics of cigarette smoking on urinary tract cancer risk: a meta-analysis of epidemiologic studies. Cancer 2000;89:630-9.

[13] Aliasgari MA, Kaviani A, Gachkar L, Hosseini-Nassab SR. Is bladder cancer more common among opium addicts? Urol J. 2004;1:253-5.

[14] Jeffrey TO, Qiang L, Nachimuthu N, Curtis JM, Michael C. Cigarette Smoking and the Risk of Bladder cancer in men and women. Tobacco Induced Disease 2004;2:141-4.

[15] Anthony J A, Anthony K, Jeanine MG, et al. A Prospective cohort study of bladder cancer risk in relation to active cigarette smoking and household exposure to secondhand cigarette smoke. American Journal of Epidemiology. 2007;165:660-6.

[16] Kiriluk KJ, Prasad SM, Patel AR, Steinberg GD, Smith ND. Bladder cancer risk from occupational and environmental exposures. Urol Oncol. 2012;30:199-211.

[17] Gago-Dominguez M, Chan KK, Ross RK, et al. Permanent hair dyes and bladder- cancer risk. Int J Cancer 2001;94:905-6.

[18] Bianco FJ: Nomograms and medicine. Eur Urol. 2006;50:884-6.

[19] Ludecke G, Weidner W. Risıkocheck $\odot$, an internet-based instrument to identify risk populations for bladder cancer: experiences of 2 years' online risk check in four languages. European Urology Supplements. 2006;5:254.

[20] Luedecke G, Turker P, Gunlusoy B, et al. Risk-adapted screening in bladder cancer as a new strategy in bladder cancer is feasible using a computer-based questionnaire, risikocheck 4.0, evaluated in an international multicenter trial European Urology Supplements. 2008;7:136.

[21] Lerner SP, Bochner B, Kibel AS: The use and abuse of data: Nomograms and talking to patients about clinical medicine. Urol Oncol. 2007;25:333-7.

[22] Ather MH, Zaidi M. Predicting recurrence and progression in non-muscle-invasive bladder cancer using European organization of research and treatment of cancer risk tables. Urol $\mathrm{J}$. 2009;6:189-93. 